Shereen Paramalingam MBBS 1.2

Yi J Kuok MBBS, RANZCR

1 Sir Charles Gairdner Hospital, Perth, WA.

2 Royal Perth Hospital, Perth, WA.

pshereen81@yahoo.com

doi: 10.5694/mjal4.01227

\title{
Snapshot
}

\section{Eagle syndrome as a potential cause of} Tapia syndrome

A 38-year-old man presented with influenza A (H1N1) pneumonia complicated by acute respiratory distress syndrome, resulting in an extended intensive care unit stay (37 days). After he was extubated, he was found to have left-side IX, X and XII cranial nerve palsies. Computed tomography of his neck showed bilateral elongated styloid processes ( $5.0 \mathrm{~cm}$ long; Figure), consistent with Eagle syndrome. ${ }^{1}$ The left styloid process was closely opposed to the transverse process of the first cervical vertebra, causing effacement of the internal jugular vein and compression of the IX, X and XII cranial nerves, which converge in this area. The eponym used to describe concurrent paralyses of the X and XII cranial nerves is Tapia syndrome, ${ }^{2}$ with prolonged neck flexion potentially contributing to the condition in our case.

Acknowledgements: Fraser Brims (Respiratory Department, Sir Charles Gairdner Hospital, Perth, WA) was the consultant who saw this patient.

Competing interests: No relevant disclosures.

Provenance: Not commissioned; externally peer reviewed.

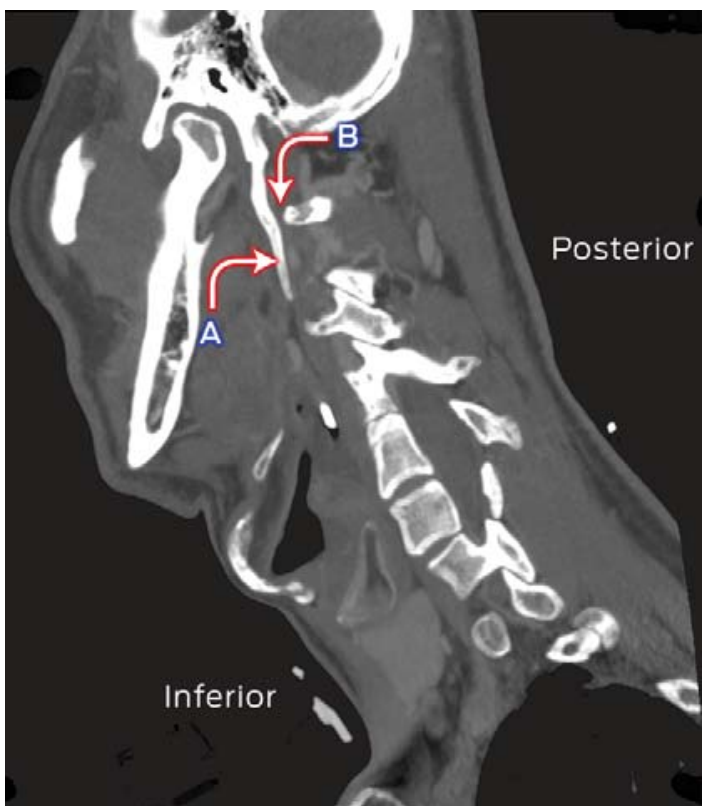

Sagittal computed tomography image of the neck of the patient. A: Elongated styloid process (left); B: Area of compression of IX, X and XII cranial nerves.

1 More CB, Asrani MK. Eagle's syndrome: report of three cases. Indian J Otolaryngol Head and Neck Surg 2011; 63: 396-399.

2 Kang JH, Kim DM, Kim SW. Tapia syndrome after cervical spine surgery. Korean J Spine 2013; 10: 249-251. 